\title{
Mutation Detection
}

National Cancer Institute

\section{Source}

National Cancer Institute. Mutation Detection. NCI Thesaurus. Code C18890.

The detection by physical, chemical, or biological means of an altered DNA sequence.

Includes SSCP, DNA sequencing, hybridization, and reporter gene expression. 